\title{
O curso de licenciatura em Ciências Naturais e a organização de seus estágios supervisionados
}

\author{
The undergraduate program in natural sciences \\ and the organization of its supervised internships
}

\author{
Renata Cardoso de Sá Ribeiro Razuck ${ }^{1}$ • Jeane Cristina Gomes Rotta ${ }^{1}$
}

\begin{abstract}
Resumo: Este artigo discute a necessária formação de Licenciados em Ciências Naturais para atuar em toda a Educação Básica, e a estruturação dos Estágios Supervisionados do referido curso. Profissionais diversos têm ocupado o cargo de professores de Ciências sem, no entanto, ter formação específica para tal. Este fato pode ser responsável pelo baixo rendimento evidenciado na área, repercutindo em toda a vida escolar do educando. Nesse cenário, o estágio supervisionado pode ser um forte eixo articulador na melhoria da formação inicial dos docentes, sobretudo no que tange ao rompimento da dicotomia entre a teoria e a prática e na constituição do estágio como espaço de pesquisa para a elaboração de projetos coletivos de formação do educador.
\end{abstract}

Palavras-chave: Ensino Superior. Ciências naturais. Formação de professores. Estágio supervisionado.

\begin{abstract}
This article discusses the necessary training of graduates in natural sciences to work in all of Basic Education and the structuring of supervised internships in that course. Many professionals have held the position of science teachers without, however, having specific training to do so. This fact may account for the low yield evidenced in the area, reverberating throughout the school life of the student. In this scenario the supervised internship can be a strong coordinating focus on improving initial teacher training, especially when it comes to breaking the dichotomy between theory and practice and the constitution of the stage as a space for research projects for developing collective educator training. Keywords: Higher Education. Natural sciences. Teacher education. Supervised internships.
\end{abstract}

\footnotetext{
${ }^{1}$ Universidade de Brasília (UnB), CEP 73061-000, Planaltina, DF, Brasil. E-mail: <renatarazuck@unb.br>
} 


\section{Introdução}

A preocupação existente com a qualidade da formação inicial dos professores é pertinente, uma vez que nos deparamos com uma grande quantidade de professores que possuem uma visão muito simplista da sua prática pedagógica e, ao mesmo tempo, encontramos licenciandos e licenciados que não se consideram bem preparados e seguros para trilharem suas jornadas como docentes (PIMENTA; LIMA, 2004; ROSA; SCHNETZLER, 2003). Neste contexto, Dias-da-Silva (2005) e Schnetzler (2002) observam que há uma ineficiência dos cursos de Licenciaturas que ainda formam seus professores baseados em uma racionalidade técnica, que se caracteriza pela separação entre a teoria e a prática.

Aliado a esse cenário, dados recentes revelam uma realidade preocupante que atinge a todos os níveis de escolarização: nossas escolas ainda têm um alto índice de evasão, com rendimento insatisfatório em diversas disciplinas, sobretudo na área de Ciências e Matemática (FERNANDES, 2007; KLEIN, 2007; RIBEIRO, 1991). Diante do fato, medidas governamentais têm sido criadas para erradicar a evasão escolar, como a implementação da Escola Ciclada, a criação do programa bolsa-escola e a criação do Plano Desenvolvimento Escolar (PDE). Entre os programas mais específicos voltados ao ensino de Ciências e Matemática, pode-se destacar o "Ciência em Foco"2 e o "Programa Xadrez nas Escolas"3. Entretanto, tais medidas ainda não têm sido suficientes para garantir a permanência e a promoção do estudante na escola. Possivelmente, uns dos principais fatores que levam à evasão escolar se relacionam com a precária formação dos professores (BORUCHOVITCH, 1999). Dessa forma, deve-se pensar, prioritariamente, a formação dos docentes com o intuito de diminuir essa distância verificada entre os alunos e as escolas, modificando, assim, esta situação excludente. No entanto, a prática pedagógica dos professores de muitas escolas brasileiras é similar às utilizadas por seus antigos professores, pois, durante a sua formação inicial, esteve ausente a valorização da construção do conhecimento científico e o contato com metodologias didáticas que favorecessem a argumentação, a investigação e a divulgação das ideias científicas.

Vale ainda ressaltar que, até o início do século XXI, na organização das Licenciaturas no Brasil, existia uma proposta específica para a formação de professores para o ensino infantil, nas séries iniciais do Ensino Fundamental e para o Ensino Médio, mas não existia uma formação específica para professores de Ciências para as séries finais do Ensino Fundamental. Essa lacuna pode ser entendida como um dos possíveis fatores responsáveis pela criação dessa ruptura na continuidade da educação.

\footnotetext{
${ }^{2}$ A Secretaria de Educação do Distrito Federal adotou o Programa Ciência em Foco para as aulas de Ciências do Ensino Fundamental no período de 2008 a 2010. Este material foi idealizado pelo Instituto Sangari com o nome inicial "CTC Ciência e Tecnologia com Criatividade" e, ao ser adotado na rede pública do DF, recebeu o nome de "Ciência em Foco". Este programa atendeu a mais de trezentos mil alunos e cerca de sete mil professores em 532 escolas.

${ }^{3}$ O Programa Xadrez nas Escolas é um projeto educacional do governo brasileiro por meio de parcerias entre o Ministério do Esporte, Ministério da Educação e as Secretarias de Estado de Esporte e Educação. Tal programa visa o estudo e a prática do xadrez como auxiliar no desenvolvimento do aluno.
} 
De acordo com Magalhães Junior e Pietrocola (2005), o ensino de Ciências no Ensino Fundamental é muito recente no Brasil e, até hoje, a formação de professores desse nível de ensino é relegada pelas universidades. Assim, a disciplina Ciências só foi inserida obrigatoriamente, na educação brasileira, a partir da Lei de Diretrizes e Bases da Educação (LDB) em 1961, pela lei no 4.024/61, mas a formação de professores foi postergada para a década de 1970. Somente a partir da promulgação da nova LDB, lei nº 9.394/96 é que se torna obrigatória a formação de nível Superior de cursos plenos para profissionais da educação, incluindo os da área de Ciências. Apesar disso, a maioria das universidades preferiu continuar formando professores em áreas específicas, e não em Ciências, de forma generalista. Segundo os autores, o ensino de Ciências no nível Fundamental é conhecido como Ciências Naturais, e ainda também, em alguns casos, como Ciências Físicas (compreendendo a Física, a Química, a Geologia e a Astronomia) e Biológicas (compreendendo a Fisiologia, Anatomia, Botânica e Zoologia). Ou seja, ainda hoje, o curso de Ciências Naturais é confundido com o de outras áreas de formação.

Para Razuck e Razuck (2011), a falta de um programa de formação específica para a Licenciatura em Ciências vem sendo suplantada, sobretudo, pelos cursos de Licenciatura em diversas áreas do conhecimento, como, por exemplo, Ciências Biológicas, Química e Física, os quais costumam atender, parcialmente, as demandas escolares. E, ainda mais alarmante, em nosso país, é cotidiano encontrarmos profissionais com formação diversa ministrando aulas de Ciências para as séries finais do Ensino Fundamental. É frequente encontrarmos biólogos, químicos, físicos, matemáticos, médicos, dentistas, agrônomos, engenheiros e veterinários, entre outras formações, atuando como professores de Ciências, o que pode ser comprometedor para o processo de ensino e aprendizagem.

Nesse cenário, a importância do estágio supervisionado, como eixo articulador na melhoria da formação inicial dos docentes, vem sendo muito discutida (CARVALHO, 2001; PIMENTA; LIMA, 2004; SCHNETZLER, 2002; SILVA, 2004), sobretudo no que consiste no rompimento da dicotomia entre a teoria e a prática e na constituição do estágio como pesquisa para a elaboração de projetos coletivos de formação do educador.

\section{A necessária formação de professores de Ciências}

Uma breve estimativa da demanda de professores de Ciências para a década 2001-2010, considerando a universalização obrigatória da Educação Fundamental, mostra que seriam ainda necessários cerca de 32 mil professores para atender o segundo segmento, relativo ao ensino do $6^{\circ}$ ao $9^{\circ}$ anos (CHAVES; SHELLARD, 2005). Além disso, as novas exigências legais indicam que os professores devem ter formação específica em Ciências Naturais (BRASIL, 2001), o que justifica a necessidade de implementação deste curso em nossas Universidades, a partir de 2006, com a proposta de formar um profissional com uma visão ampla, integrada e interdisciplinar das áreas de Química, Biologia, Física e Geologia.

Assim, de acordo com a UNESCO e segundo o Conselho Internacional para a Ciência, durante a Conferência Mundial sobre a Ciência para o Século XXI, realizada em Budapeste no ano de 1999: 
Para um país ter a capacidade de atender às necessidades básicas da sua população, a educação científica e tecnológica é uma necessidade estratégica. Como parte dessa educação, os alunos devem aprender a solucionar problemas específicos e a abordar as necessidades da sociedade, utilizando os seus conhecimentos e as suas habilidades científicas e tecnológicas. (DECLARAÇÃO..., 1999, p. 13)

Como proposta para suprir essa falta de profissionais para atuarem na Educação Básica, o MEC tem se preocupado com a formação de novos professores para atender a área de Ciências (Química - Física - Biologia). Em 2009, o MEC implantou o Programa Emergencial de Segunda Licenciatura para Professores em exercício na Educação Básica Pública. De acordo com Costa (2010, p. 24), o governo tem implantado diversas medidas que demonstram preocupação com a formação de professores, tais como: “o Edital CT-INFRA/FINEP-01/2003; a Chamada Pública MEC/SEED-001/2004; e o Programa Pró-Licenciatura Resolução CD/ FNDE n 34, de 9 de agosto de 2005 [...]".

Visando superar os problemas da formação inicial de professores, muitas universidades estão se reestruturando e realizando reformas curriculares, de tal forma que possam garantir uma melhoria na formação dos docentes. O surgimento de novos cursos de Licenciaturas em Ciências Naturais em todo o país é relatado por Imbernon et al. (2011), sendo que dez universidades já ofertam esse curso.

As reformas curriculares estão sendo realizadas, em âmbito mundial, desde a década de 1980, e consideram a formação do professor como elemento-chave da reforma educacional. De acordo com Villani, Pacca e Freitas (2002), a formação inicial dos professores de ciências no Brasil, nos últimos cinquenta anos, foi fortemente influenciada por fatos educacionais, sociais e políticos que ocorreram no exterior. Na década de 1970, Portugal iniciou reformas para a melhoria da formação inicial de professores; porém, no Brasil, tais reformas só foram iniciadas na primeira década do século XXI, sendo basicamente impulsionadas pela carência de professores de Ciências na Educação Básica e devido às orientações das novas normativas legais como a LDB de 1996 e as Diretrizes Curriculares (ECHEVERRÍA, 2004).

Com a aprovação da Lei de Diretrizes e Bases da Educação Nacional (LDB) em 1996 (BRASIL, 1996), compete ao Conselho Nacional de Educação (CNE) definir as diretrizes curriculares para todos os cursos de graduação no País. No entanto, o curso de Licenciatura em Ciências Naturais não possui, até o momento, diretrizes curriculares que orientem a formação desse docente.

Desta forma, as universidades têm contribuído com muitas propostas, tanto no sentido de melhorar a formação inicial dos professores, quanto para atender as exigências das Diretrizes Curriculares Nacionais. Entre estas propostas, podemos destacar as contribuições dos pesquisadores da área de ensino em química, que, de acordo com Schnetzler (2002), são basicamente: a criação de núcleos de pesquisa em educação química nos departamentos e institutos de química das universidades e a tríade de interação profissional entre os licenciandos, professores universitários e professores do Ensino Médio, que também visa atender a atual legislação que determina quatrocentas horas de prática de ensino vivenciadas desde o início do curso de licenciatura e quatrocentas horas de estágio supervisionado ao final do mesmo. Além disso, Maldaner (2000) discute os problemas enfrentados na formação inicial dos professores e as possibilidades de 
formação do professor reflexivo e pesquisador de sua própria prática. De acordo com Schnetzler (2002), existe uma deficiência de propostas, pelas universidades, que incentivem a pesquisa no ensino e sobre o ensino, para que a produção de conhecimentos acadêmicos possa auxiliar na formação da identidade do professor. Barcelos e Villani (2006) relatam, especificamente nos casos dos estágios supervisionados, que apesar de haver experiências positivas de escolas que acompanham a atuação dos estagiários, contribuindo, realmente, para a formação inicial desses, ainda faltam projetos que aproximem as instituições de Ensino Básico e Superior

Portanto, como já sinalizado, depreende-se a necessidade, cada vez maior, de se implementarem cursos de Licenciaturas em Ciências que formem um professor com uma consciência crítica e com visão ética e social. Para que ocorra a formação de um docente pesquisador reflexivo de sua prática docente (MALDANER, 2000), é necessária a criação de um ambiente favorável. Neste âmbito, Pimenta e Lima (2004), e Silva (2004) discutem a importância do estágio no processo de formação do professor, pois este deve ser um campo onde ocorra análise, investigação e interpretação crítica, a partir dos nexos com as disciplinas do curso (interdisciplinaridades) e servindo, assim, como uma busca para responder às situações que desafiam o aluno estagiário na educação, e auxiliando o professor a reconhecer-se ou não na profissão. Pois o professor de Ciências Naturais que irá atuar nas séries finais do Ensino Fundamental (EF), será reflexo das suas concepções sobre o que é ensinar e como se aprende. Portanto, acredita-se na importância de um curso de formação inicial capaz de propiciar a base científica e pedagógica adequada para a formação de um docente capaz de atuar de forma coerente com as necessidades educacionais de um estudante do EF que tem um perfil cognitivo diferente do aluno do Ensino Médio (EM).

Desta forma, como o estágio pode emergir como um campo de integração entre teoria (ensino) e prática (realidade de trabalho), e conduzir a uma aproximação entre a realidade da escola e as disciplinas do curso de formação, além de fornecer um ambiente favorável para a formação do professor reflexivo/pesquisador? Para Fazenda (2001), alguns cursos de formação de professores consideram o estágio como o "salvador da pátria”, e se esquecem ou não possuem consciência das dificuldades com que se defrontaram para implantar um estágio que atenda as expectativas explicitadas anteriormente, pois a tradição em pesquisa é algo que não se adquire do dia para a noite. Sendo assim, qual deve ser a metodologia dos professores orientadores de estágio, junto com os seus pares e alunos, para analisarem e questionarem, criticamente, à luz das teorias, as realidades observadas no cotidiano escolar? Como elaborar projetos de pesquisa/ intervenção que sejam reflexos destas observações? Buscar responder a essas questões visando uma possibilidade de efetivar uma maior integração entre a escola e universidade, almejando a melhoria da Educação é realmente um grande desafio...

\section{O Curso de Licenciatura em Ciências Naturais na Universidade de Brasília}

Sabe-se que a Universidade de Brasília tem, hoje, uma política clara de extensão, que permite não só a vasta produção de conhecimento nos projetos de extensão, desenvolvidos como projetos de pesquisa, como, também, a participação dos estudantes nestas atividades. Acreditase que a extensão é um importante eixo norteador das atividades que devem ser desenvolvidas dentro do âmbito universitário. Rotta et al. (2012) e Porto et al. (2011) relatam a importância das 
atividades de extensão que contribuem como fonte de pesquisas acadêmicas, conhecimento da realidade das escolas e na busca de soluções, difusão e socialização do conhecimento gerado no âmbito acadêmico, aprendizado do saber popular e possibilita a inter-relações entre os saberes. As práticas extensionistas estão presentes no processo de formação de professores de Ciências Naturais e podem propiciar, à formação inicial do professor de Ciências, espaços para integração dos conhecimentos teóricos com as práticas docentes. Da interação dos licenciandos com o ambiente escolar, surgem demandas de atividades experimentais sugeridas pelos professores da Educação Básica. A construção coletiva desse experimento, com os professores da escola e da universidade, é um desafio aos futuros professores a pesquisarem propostas de experimentação investigativa, contextualizada, envolvendo aspectos da história das Ciências e uma abordagem ciência/tecnologia/sociedade/ambiente (CTSA). Nesse contexto, percebe-se a possibilidade de integração do trinômio ensino, pesquisa e extensão, pois os licenciandos precisam mobilizar todo o seu arcabouço de conhecimentos teóricos para pesquisarem respostas advindas da comunidade escolar, com a orientação do professor universitário. O momento em que retornam à escola para desenvolverem a atividade experimental, é profícuo para conhecerem os saberes escolares e docentes necessários para a sua formação, propiciando articular a teoria e prática docente. Percebe-se como que a teoria influencia a prática, podendo modificá-la, da mesma maneira que a prática fornece subsídios para a teorização que a transforma, estabelecendo, assim, "a prática da reflexão".

Os docentes de Ciências da Educação Básica podem, de forma significativa, contribuir para a formação discente. Assim, propõe-se uma metodologia diferenciada com relação às disciplinas oferecidas, como no caso da disciplina de Estágio Supervisionado em Ensino de Ciências Naturais, que almeja possibilitar esta formação, na qual todos os envolvidos (alunos da Educação Básica, licenciandos, professores da Educação Básica e das Instituição de Ensino Superior) trabalham colaborativamente e aprendem com tal experiência. Em outras palavras, busca-se integrar pesquisa e extensão, propiciando intervenção sobre a realidade e a produção de conhecimento, envolvendo os estudantes neste processo.

Para tal, tem-se como base a questão do trabalho em Vigotski (2003), o qual defende que o trabalho deve ser a própria base do processo educativo, por possibilitar a articulação entre os estudos escolares e o cotidiano, com o intuito de alcançarmos um maior envolvimento, interesse e aprendizagem. Essa articulação pode ser perfeitamente viabilizada a partir de projetos pedagógicos, os quais surgem da necessidade de desenvolver uma metodologia de trabalho que valorize a participação do educando e do educador no processo de ensino e aprendizagem, e visa transformar o espaço escolar em um local de interações, aberto ao real e às suas múltiplas dimensões.

O trabalho construído com base no sistema das reações conscientes é justamente essa ponte que se estende entre o mundo das ciências naturais e o das ciências humanas. É a única "matéria" que constitui o objeto de estudo de ambas.

Só o trabalho, em seu significado histórico e em sua essência psicológica, é o ponto de encontro entre o fundamento biológico e o suprabiológico no ser humano. Nele se enlaçaram o animal e o homem, e o saber humano e o natural se entrecruzaram. Portanto, a síntese na educação, com 
a qual sonhavam os psicólogos em tempos remotos, torna-se possível na educação para o trabalho (VIGOTSKI, 2003, p. 193).

Como sugere Freire (1997), ao se trabalhar com projetos, tem-se a possibilidade de reflexão sobre a correlação entre o tema estudado e a realidade social, e não apenas sobre o conteúdo de uma disciplina isolada. Na verdade, os projetos oportunizam uma abordagem global de conteúdos a partir dos temas de interesse da comunidade, o que faz com que esta abordagem seja sempre inter e multidisciplinar, com o enfoque voltado para a formação cidadã.

Esse processo acaba, também, por criar, junto ao corpo discente, um perfil de pesquisador, fundamental na sua vida como professor. A formação de um professor-pesquisador, como apontado por Moreira (1998), é essencial para uma verdadeira melhoria do ensino das Ciências, tendo muito a contribuir, sobretudo com relação à pesquisa com fundamentação teórica e epistemológica, uma vez que o próprio professor está em posição privilegiada para coletar dados e investigar situações de ensino e aprendizagem na sala de aula.

Assim, para o autor, no ensino de Ciências, grande parte dos esforços de pesquisa é dedicada à investigação para solução de problemas, seja em laboratório, seja sobre concepções espontâneas dos alunos. Já o professor, por outro lado, trabalha, diariamente, em situações reais de sala de aula, essas mesmas questões.

Portanto, para Erickson (1986, p. 157, tradução nossa):

O professor, como pesquisador de sala de aula, pode aprender a formular suas próprias questões, a encarar a experiência diária como dados que conduzem a respostas a essas questões, a procurar evidências não confirmadoras, a considerar casos discrepantes, a explorar interpretações alternativas. Isso, pode-se argumentar, é o que o verdadeiro professor deveria fazer sempre. A capacidade de refletir criticamente sobre sua própria prática e de articular essa reflexão para si próprio e para os outros, pode ser pensada como uma habilidade essencial que todo professor bem preparado deveria ter.

Nesse contexto, com o intuito de cumprir seu papel social formando educadores que possam suprir a carência de professores de Ciências em nosso país, a Universidade de Brasília (UnB) criou, em 2005, o curso de Licenciatura em Ciências Naturais na Faculdade UnB Planaltina, que tem como objetivo central a formação de um licenciado em Ciências Naturais para atuar na Educação Básica.

Nesse curso, a Ciência não é vista apenas como um meio de compreender os produtos tecnológicos, mas, sobretudo, como um processo de pensar o mundo em busca de soluções equilibradas, o que confere caráter interdisciplinar e muito contribui não só para a formação intelectual, mas, também, moral de nossos educandos e futuros professores.

Segundo o Projeto Político Pedagógico do curso:

Estudar Ciências Naturais tem implicações importantes relacionadas à compreensão do mundo e suas transformações, e ao conhecimento científico, passando pela formação de cidadãos reflexivos e críticos, com 
capacidades diversas para analisar, questionar e modificar a sociedade e o ambiente a sua volta, de modo responsável, e respeitando as pessoas e todas as outras formas de vida. (UNIVERSIDADE DE BRASÍLIA, 2010, p. 9)

Nesse sentido, não há como ensinar Ciência de forma desconexa da pesquisa e da necessária formação contínua do professor, na qual sua prática pedagógica deve ser sempre investigada e refletida, gerando pesquisas que possibilitem a produção de novos conhecimentos sobre o ensino de Ciências.

Assim, segundo o próprio Projeto Político Pedagógico, o curso de Licenciatura em Ciências Naturais da UnB "busca o enfoque interdisciplinar das Ciências e utiliza a pesquisa como instrumento pedagógico para a formação de educadores, visando atender uma demanda crescente de profissionais” (UNIVERSIDADE DE BRASÍLIA, 2010, p. 10).

Pelo exposto até o momento, fica claro que a formação de professores exige hoje que se supere o modelo tradicional de formação, constituído, anteriormente, pela simples soma de dois conjuntos isolados (PIMENTA; LIMA, 2010): a formação estrita em conhecimentos específicos ("conteúdos") e a formação teórica estrita em pedagogia ("formas e técnicas de ensinar"). A busca pela superação dessa visão dicotômica é um grande desafio vivenciado ao longo do curso.

Pimenta e Lima (2004) também ressaltam a importância da pesquisa no estágio, no qual, por um lado, ocorre a realização de pesquisas que permitam um melhor entendimento e análise dos contextos onde estão se realizando o estágio; e por outro, o estagiário pode desenvolver postura e habilidade de pesquisador a partir das situações observadas e elaborar projetos que viabilizem, ao mesmo tempo, compreender e problematizar as situações que os cercam, exercitando a sua criatividade e cidadania.

Acredita-se que as disciplinas de estágio supervisionado (que totalizam 400h, conforme a atual legislação) sejam cruciais para os aspectos da formação inicial e continuada de professores, conforme apresentados a seguir.

\section{As disciplinas de estágio supervisionado e o Ensino de Ciências}

As disciplinas de Estágio Supervisionado buscam contemplar a interdisciplinaridade, a integração dos conteúdos específicos, os pedagógicos e a prática docente, junto com a escola formadora (Resolução CNE/CP 009/2001). Assim, o estágio supervisionado engloba um conjunto de atividades de formação, realizadas sob a supervisão de docentes da instituição, visando a vivência de situações de efetivo exercício profissional.

O Estágio Supervisionado curricular do curso de Licenciatura em Ciências da Faculdade UnB Planaltina (FUP) está de acordo com as leis de Diretrizes Curriculares para a Formação de Professores de 2001, que regulamentam as quatrocentas horas de estágio supervisionado; e inicia-se a partir do quinto e sexto semestre nos cursos diurno e noturno, respectivamente, sendo pré-requisito a disciplina Didática das Ciências. As quatrocentas horas estão divididas em quatro semestres, nas disciplinas Estágio Supervisionado em Ensino de Ciências Naturais (ESECN) 1, 2, 3 e 4, totalizando 405 horas, o que equivale a 27 créditos. 
Buscando atender a proposta do projeto político pedagógico do curso, que visa formar um licenciado em Ciências Naturais que possa atuar no Ensino de Ciências na Educação Básica, as duas primeiras disciplinas de estágio dois são realizadas nos anos finais do Ensino Fundamental. A partir das ementas dessas disciplinas, pode-se observar a preocupação para que o licenciando vivencie situações concretas do processo de ensino e aprendizagem por meio da observação do ambiente escolar e regência. Na disciplina ESECN 1, é o momento de familiarização com o cotidiano escolar, onde o licenciando poderá vivenciar a rotina do professor, e dos demais atores que compõem a comunidade escolar, tais como: a Coordenação Pedagógica, Direção Escolar e os alunos. Esse também é o momento de análise e discussão do projeto político pedagógico da escola, suas relações com o currículo e com a avaliação.

A disciplina ESECN 2 prevê a elaboração, aplicação e avaliação de projetos de ensino adequado à realidade de cada escola nas séries finais do Ensino Fundamental, sendo tais projetos amplamente discutidos com o professor responsável pela disciplina previamente a sua aplicação. A elaboração desses projetos de intervenção podem surgir de pesquisas realizadas pelos estagiários na disciplina (ou em outras disciplinas ao longo do curso), como, também, podem estar associadas às demandas da escola. Em ambas as situações, o licenciando precisa pesquisar para poder elaborar um projeto que possa atender as situações- problemas. De acordo com Pimenta e Lima (2004), a pesquisa no estágio é muito importante, pois, de um lado, ocorre a realização de pesquisas que permitam um melhor entendimento e análise dos contextos onde está se realizando o estágio; por outro, o estagiário pode desenvolver postura e habilidade de pesquisador a partir das situações observadas e elaborar projetos que viabilizem, ao mesmo tempo, compreender e problematizar as situações que os cercam, exercitando a sua criatividade e cidadania.

Assim, o estágio pode ser o eixo articulador para melhorar a formação inicial dos docentes, sobretudo no que consiste no rompimento da dicotomia entre a teoria e a prática e na constituição do estágio como pesquisa para a elaboração de projetos coletivos de formação do educador (CARVALHO 2001; PIMENTA; LIMA, 2004; SCHNETZLER, 2002; SILVA, 2004).

As disciplinas ESECN 3 e 4 apresentam ementas semelhantes às mencionadas anteriormente, com exceção do fato de serem desenvolvidas no Ensino Médio. No entanto, a disciplina ESECN 4 prevê, também, a realização do estágio supervisionado em ambientes informais de ensino de ciências e em escolas com ensino diferenciado, tais como Educação de Jovens e Adultos (EJA). Dessa forma, visa-se oferecer, aos futuros docentes, uma visão mais ampla acerca da atuação dos professores nos diferentes segmentos da Educação Básica.

As quatro disciplinas têm como base, para avaliação dos estagiários, os portfólios, que contêm os relatos e reflexões dos momentos de estágio. Sobre esta nova luz, os estágios possibilitaram a veiculação das contribuições sobre a concepção do professor como profissional reflexivo e capaz de produzir conhecimento (SCHÖN, 1992). Esta compreensão leva a um direcionamento do estágio para um novo foco de análise das relações entre as teorias existentes e a realidade apresentada nas escolas, o que possibilitará, aos licenciandos, uma compreensão da complexidade das práticas institucionais e das ações ali praticadas por seus profissionais, aproximando-os da realidade e visando uma melhoria na prática docente (PIMENTA; LIMA, 2004).

Além disso, estudos apontam que o Estágio Supervisionado propicia a formação do professor pesquisador, já que pressupõe a pesquisa como prática e pode, também, ser um indutor de formação continuada para o professor da Educação Básica que recebe o estagiário 
(PIMENTA; LIMA, 2010). Nesse sentido, podemos dizer que o estágio supervisionado é de fundamental importância para a constituição da área de ensino de Ciências, pois propicia a aproximação da pesquisa acadêmica à prática da sala de aula, possibilitando que licenciando e licenciado se apropriem das recentes pesquisas em Didática da Ciência.

\section{Referências}

BARCELOS, N. N. S.; VILLANI, A. Troca entre universidade e escola na formação docente: uma experiência de formação inicial e continuada. Ciência \& Educação, Bauru, v. 12, n. 1, p. 73-97, 2006.

BORUCHOVITCH, E. Estratégias de aprendizagem e desempenho escolar: considerações para a prática educacional. Psicologia: reflexão \& crítica, Porto Alegre, v. 12, n. 2, p. 361-376, 1999.

BRASIL. Lei ${ }^{\circ}$ 9.394, de 20 de dezembro de 1996. Estabelece as diretrizes e bases da educação nacional. Brasília: Presidência da República, 1996. Disponível em: <http://www.planalto.gov.br/ ccivil_03/Leis/L9394.htm>. Acesso em: 10 jul. 2010.

BRASIL. Ministério da Educação. Parecer CNE/CP 009/2001. Diretrizes curriculares nacionais para formação de professores da educação básica, em nível superior, curso de licenciatura, de graduação plena. Brasília: Conselho Nacional de Educação, 2001. Disponível em: < http://portal. mec.gov.br/cne/arquivos/pdf/009.pdf>. Acesso em: 18 dez. 2010.

CARVALHO, I. C. de M. Qual educação ambiental?: elementos para um debate sobre educação ambiental popular e extensão rural. Agroecologia e Desenvolvimento Rural Sustentável, Porto Alegre, v. 2, n. 2, p. 43-51, 2001.

CHAVES, A.; SHELLARD, R. C. Física para o Brasil: pensando o futuro. São Paulo: Sociedade Brasileira de Física, 2005.

COSTA, N. L. A formação do professor de ciências para o ensino da química do $\mathbf{9}^{\circ}$ ano do ensino fundamental: a inserção de uma metodologia didática apropriada nos cursos de licenciatura em ciências biológicas. 2010. 75 f. Dissertação (Mestrado em Ensino das Ciências na Educação Básica) - Escola de Educação, Ciências, Letras, Artes e Humanidades, Universidade do Grande Rio "Prof. José de Souza Herdy", Duque de Caxias, 2010.

DECLARAÇÃO sobre a ciência e o uso do conhecimento científico: versão adotada pela Conferência de Budapeste, 1 de julho de 1999. Disponível em: <http://www.dominiopublico.gov. br/download/texto/ue000111.pdf > Acesso em: 18 dez. 2010.

DIAS-DA-SILVA. M. H. F. Política de formação de professores no Brasil: as ciladas da reformulação das Licenciaturas. Perspectiva, Florianópolis, v. 23, n. 2, p. 381-406, 2005. 
ECHEVERRÍA, A. R. Mudanças curriculares e a formação de professores. Saberes e Fazeres do Educador em Química - Fenômeno de Múltiplas Áreas. In: ENCONTRO DE DEBATES SOBRE DE ENSINO DE QUÍMICA, 24., 2004, Caxias do Sul. Anais... Caxias do Sul: UCS, 2004. p. 1-18.

ERICKSON, F. Qualitative methods in research on teaching. In: WITTROCK, M. C. (Ed.).

Handbook of research on teaching. 3. ed. New York: Macmillan, 1986. p. 119-161.

FAZENDA, I. C.A. Dicionário em construção: interdisciplinaridade. São Paulo: Cortez, 2001.

FERNANDES, R. Índice de desenvolvimento da educação básica (Ideb). Brasília: Instituto Nacional de Estudos e Pesquisas Educacionais Anísio Teixeira, 2007.

FREIRE, P. Pedagogia da autonomia. Rio de Janeiro: Paz e Terra, 1997.

IMBERNON, R. A. L. et al. Um panorama dos cursos de licenciatura em ciências naturais (LCN) no Brasil a partir do $2^{\circ}$ Seminário Brasileiro de Integração de Cursos de LCN/2010. Experiências em Ensino de Ciências, Cuiabá, v. 6, n. 1, p. 85-93, 2011.

KLEIN, R. Universalização do ensino básico. O Globo, Rio de Janeiro, 21 jan. 2007. Opinião, p. 07. Disponível em: <http://www.clipping.uerj.br/0008497_v.htm >. Acesso em: 17 jul. 2014.

MAGALHÃES JÚNIOR, C. A.; PIETROCOLA, M. A formação dos professores de ciências para o ensino fundamental. In: SIMPÓSIO NACIONAL DE ENSINO DE FÍSICA, 16., 2005, Rio de Janeiro. Resumos... Rio de Janeiro: Sociedade Brasileira de Física, 2005. p. 1-4. Disponível em: $<$ http://www.sbf1.sbfisica.org.br/eventos/snef/xvi/cd/resumos/t0602-1.pdf > . Acesso em: 16 jul. 2014.

MALDANER, O. A. A formação inicial e continuada de professores de química: professores/ pesquisadores. Ijui: Editora Unijui, 2000. v. 1.

MOREIRA, M. A. O professor-pesquisador como instrumento de melhoria do ensino de ciências. Em Aberto, Brasília, v. 40, p. 43-54, 1988.

PIMENTA, S. G.; LIMA, M. S. L. Estágio e docência. São Paulo: Cortez, 2004.

PIMENTA, S. G. ; LIMA, M. S. L. Estágio e docência. 5. ed. São Paulo: Cortez, 2010.

PORTO, F. de S. et al. Experimentação como estratégia para o ensino de ciências: reflexões sobre a formação inicial de professore a partir de um projeto no laboratório de ensino. In: ENCONTRO NACIONAL DE PESQUISA EM EDUCAÇÃO EM CIÊNCIAS, 8., 2011, Campinas. Atas... Disponível em: <http://www.nutes.ufrj.br/abrapec/viiienpec/resumos/R0220-1.pdf >. Acesso em: 16 jul. 2014.

RAZUCK, R. C. S. R.; RAZUCK, F. B. O enfoque CTS na formação de professores em ciências um estudo de caso da Universidade de Brasília. In: SIMPÓSIO NACIONAL DE TECNOLOGIA E SOCIEDADE, 4., 2011, Curitiba. Anais... Disponível em: <http://www.esocite.org.br/eventos/ tecsoc2011/cd-anais/arquivos/pdfs/artigos/gt003-aeducacao.pdf>. Acesso em: 16 jul. 2014. 
RIBEIRO, S. C. A pedagogia da repetência. Estudos Avançados, São Paulo, v. 5, n. 12, p. 7-21, 1991.

ROSA, M. I. F. P. S.; SCHNETZLER, R. P. A investigação-ação na formação continuada de professores de Ciências. Ciência \& Educação, Bauru, v. 9, n. 1, p. 27-39, 2003.

ROTTA, J. C. G. et al. Um projeto de extensão universitária como perspectiva para a realização das práticas de ensino em um curso de formação de professores. In: ENSINO superior: inovação e qualidade na docência. Porto: CIEE, 2012. v. 1, p. 5255-5267.

SCHNETZLER, R. P. Concepções e alertas sobre formação continuada de professores de química. Química Nova na Escola, São Paulo, n. 16, p. 15-20, 2002.

SCHÖN, D. Formar professores como profissionais reflexivos. In: NÓVOA, A. Os professores e sua formação. Lisboa: Dom Quixote, 1992. p. 79-92.

SILVA, M. A. A atual legislação educacional brasileira para formação de professores: origens, influências e implicações nos cursos de Licenciatura em Matemática. 2004. 188 f. Dissertação (Mestrado em Educação Matemática) - Faculdade de Matemática, Pontifícia Universidade Católica de São Paulo, São Paulo, 2004.

UNIVERSIDADE DE BRASÍLIA. Projeto político pedagógico do curso de ciências naturais. Planaltina: Universidade de Brasília, 2010.

VIGOTSKI, L. S. O esclarecimento psicológico da educação pelo trabalho. In: Psicologia pedagógica: edição comentada. Porto Alegre: Artmed, 2003. p. 181-196.

VILLANI, A.; PACCA, J. L. A.; FREITAS, D. Formação do professor de ciências no Brasil: tarefa impossível? In: ENCONTRO DE PESQUISA EM ENSINO DE FÍSICA, 8., 2002, Águas de Lindóia. Anais... Disponível em: <http://www.sbf1.sbfisica.org.br/eventos/epef/viii/PDFs/ CO21_3.pdf>. Acesso em: 16 jul. 2014.

Artigo recebido em 30/08/12. Aceito em 06/08/13. 